\title{
Research on the Multiple Knowledge Ecological Education System of MOOCs Learning Platform in Independent Colleges
}

\author{
Weilin $\mathrm{Li}^{*}$ \\ Xinhua College of Sun Yat-sen University \\ Guangzhou 510520, China \\ lwl_tech@126.com
}

\author{
Zhiping Wan \\ Xinhua College of Sun Yat-sen University \\ Guangzhou 510520, China \\ wzp888_0@126.com
}

\author{
Feng Wang \\ Xinhua College of Sun Yat-sen University \\ Guangzhou 510520, China \\ 78133090@qq.com
}

\begin{abstract}
With the rapid development of MOOCs, many colleges have adopted the MOOCs learning platform or use it to carry out online course education. However, there are many problems involved; certain impact has formed on the traditional classroom. As the era of post-MOOCs, how can independent college carry out teaching using this method? There are some ways to counter it. To further improve the teaching quality is the key point in this paper, establishing the multi-mixture education model in MOOCs learning platform and constructing the ecological learning system is the key to carry out online education. From the integration of management, education, service, teachers and resource center to better establish corresponding knowledge ecosystem, independent college can make full use of the open characteristic of MOOCs and bringing high-quality teaching resources from various disciplines applied into the practice of curriculum reform.
\end{abstract}

Keywords-MOOCs; Online education courses; Multi-mixture; Knowledge ecology

\section{INTRODUCTION}

Since the Massive Open Online Courses (MOOC) concept has proposed, from the establishment of well-known college alliance to builds open platform to sweep across the globe, a wave of education model reform and research has set off in recent years. Year of 2012 was also known as the first year of MOOCs. The rise of MOOCs is making huge change of higher education system in today's world, which mainly reflected in the education teaching model on the time and space changes, namely MOOCs openness has made education get rid of the restriction of time and space, therefore, students can learn anytime and anywhere through online open courses. At home and abroad, many colleges, educational institutions, Internet companies have stepped into the wave of research and application of MOOC, as well as many educational experts, research scholars and researchers have studied this new education model from different perspectives, which made an important contribution to the research and practice of MOOCs, and has made a lot of research results[1]. Year of 2013 was known as the first year of Chinese MOOCs, Peking University, Tsinghua University and other domestic famous universities and institutions have joined the foreign MOOC platform, also actively explore the construction of Chinese MOOCs platform. Localization of MOOCs platforms such as XuetangX, Chinese MOOCS, CNMOOC, Could classroom of Netease have sprung up like mushrooms[2]. As the new mechanisms and new models that permitted by the country, independent colleges have a more flexible training system, but there is a widespread shortage of funds and quality teachers. Students tend to be personality, unconventional, have diverse employment direction and strong desire for knowledge in different subject areas. It is under such advantages and disadvantages, independent college can make full use of the open characteristic of MOOCs and bringing high-quality teaching resources from various disciplines applied into the practice of curriculum reform, so that the students would have more initiative in the selection of learning.

\section{THE CURRENT SITUATION OF MOOCS LEARNING PLATFORM IN INDEPENDENT COLLEGE}

The domestic independent college exploration and research the reform of education model that MOOCs will bring about is still in the initial stage at present. From the existing MOOCs, it is the collection of "huge" and "diversity" of students that different from the traditional teaching method. Thousands of students can be in the same course even if they are in different places. Therefore, it is easy to deduce that MOOCs will have a huge impact on Chinese traditional college education in the future according to the development of MOOCs. Under the era of Internet, the development of MOOCs is inevitable, and its effectiveness will gradually be integrated into our teaching. As the new independent college, it should follow closely by the pace of the times, enterprising and continuously injected fresh blood for their survival and development. Seizing the new development opportunity of educational reform of MOOCs in 
this cross century, striving to be the pioneer of the wave in the reform of higher education.

Since the inception in 1999, independent college had gone through 18 years, at the very beginning, it started from the basic construction, most of the independent college completed infrastructure and their scale is gradually stable. Later, most of the independent college began on improving the scientific research and improve the teaching quality, this period is particularly important. But independent college teaching situation is not optimistic, especially teachers is formed with its parent-college appointed and young full-time teachers of the college. Their benefits and career development prospects have a big gap compare with public colleges, so the mobility of teacher is high, the teacher's teaching experience and teaching level and the teaching quality and effect are insufficient. As well as domestic well-known colleges, many educational institutions have built the MOOCs platform. Independent colleges generally take the approach of incorporate MOOC into the general course and public elective course; thereby reduce the number and the cost of these courses. There are also independent college teachers to record their school's own courses to implements flipped classroom instruction based on the MOOCs, also carried out on the application and research of MOOCs teaching. MOOCs also have its disadvantages at this stage, for example, in the protection of intellectual property rights is weak; drop-out rate is relatively high; knowledge of replication is exaggerated; learning in MOOCS could not get a degree certificate; analysis of levels of learning is relatively low. How to address the shortcomings of MOOCs combined with the characteristics and its flexible mechanism to explore a new way in education development of independent college, which is the future development of MOOCs need to think about.

\section{THE CONSTRUCTION OF MULTI-MIXED KNOWLEDGE ECOLOGICAL EDUCATION SYSTEM OF MOOCS LEARNING PLATFORM IN INDEPENDENT COLLEGES.}

\section{A. The implement of diversified resource sharing}

Through MOOCS diversified resource sharing method, establish a public course sharing service platform to provide excellent course for traditional colleges. Not only can independent college solves the problem of insufficient resources, but also gives everyone the opportunities and ways to accept the quality of higher education. It will provide a new breakthrough to solve the outstanding problems of our country's high quality resources, and improve the popularization speed of our country's higher education.

\section{B. Create a flexible flipped classroom}

Through the Internet technology and social media platform resources, using flipped classroom model that combining with the form of online, offline and the virtual environment, to promote the actual teaching. Online form includes online learning, online guidance, and online practice; complete the relevant theoretical knowledge of learning. Offline form mainly take project training and quality course as the dominant direction, through the actual process of practice, implementation of the improvement target of curriculum teaching and students' comprehensive ability, to get the effective testing and feedback on the theoretical knowledge learning of students at the present stage. It is conducive to the students to master their own learning situation, and promote the further improvement of the learning effect. MOOCs can comprehensively and systematically master the learning features of students, learning behavior and learning process; by the statistical analysis of a large amount of relevant data and information, to analyze the students' thinking ability, analysis ability and problem solving ability, so as to realize the goal of true meaning of the long teaching objectives, to ensure the quality of personnel training.

\section{Promoting the mixed mode of teaching}

Because of the global characteristics of the network that MOOCs covered with, the best teaching effect can be preserved and spread, while the other teachers' practical work properties will change accordingly. The main work function isn't teaching, but the education work of teaching. MOOCs directly produce a lot of data information on learners' learning and teaching activities, which are conducive to the promotion of the mixed mode of teaching, also will establish from the hypothesis phase of the research on the learning theory and teaching theory based on the analysis of data information. The traditional pattern of classroom teaching is usually a teacher with a group of students, as many as there are hundreds of students, and MOOCs is a teacher will face hundreds of thousands of students; the relationship between teachers and students will change correspondingly. Students can make appropriate evaluation among different teachers, choosing teacher freely, and learners can learn from each other to help, exercise a mutual exchange of score, and question the related issue. This group of learners can really form a learning community, to promote the transformed of teacher centered model into student centered model. And through the MOOCs will be synchronized to the cloud classroom by the use of flipped classroom in realistic teaching. Traditional campus classroom study and discussion can be through online courses video feedback to the society, network platform on the course of study discussion and reflection can also return in a timely manner to the classroom, the synchronous discussion of classroom and the outside world, in order to achieve more meaningful and more able to reflect the teaching of social views of the teaching interaction.

\section{Reconstruction of open curriculum system}

In the course of study, the open interaction between teachers and students, or students and students, is an important part of improving the learning effect. MOOCs can by the evaluation of automatic machine testing interactive exercises and tests, help learners to feedback learning instantly. Break through the limitation of traditional mode of knowledge transmission in the distance education, can better guide students to learn, so as to promote the further improvement of the learning effect. Machine automatic evaluation can ensure the realization of "large scale" target; open interactive practice tends to develop in advanced forms, such as multimedia courseware, game based learning, virtual lab, automatic question and answer, are conducive to enhance the openness of learning space. Different region of students can discuss on a 
specific problem according to their own thinking. This will not only be able to incorporate the traditional learning system, but also the formation of a broader learning community concerning to the traditional curriculum. Through the tools of systematic data mining and machine learning, combining the macro and micro level analysis and grasp the hidden rules, to encourage teachers to master the students' learning situation at any time, and feedback effectively, guidance in time, which is conducive to the reconstruction of open curriculum system.

\section{E. Non classroom supplement to ground education}

MOOCs can form a complementary teaching mode with the classroom teaching, which is based on the curriculum teaching in the school, also the content of the MOOCs curriculum as the supplement or enhance, embed or reference of the school curriculum resources. Through MOOCs courses to enhance students' understanding and mastery of the curriculum knowledge, provide great help to school teacher in teaching non-school courses. This combination of MOOCs curriculum and the school teaching methods, making use of the excellent resources of global university to serve their own school students in the school curriculum has become possible, which can make independent college have the opportunity for students face-to-face to excellent courses, in order to better improve the teaching situation, Shorten the gap between domestic and foreign first-class universities in the teaching quality.

\section{F. Integrating the concept of creative education}

We cannot ignore the cultivation of students' innovative spirit while in the large-scale development of MOOCs education; especially teachers' guide and courses are very important association. Our school have specialized Maker laboratory and specialized Maker teacher, for all students to carry out creative education, essentially a Maker teacher learning interactively with the Maker laboratory at Massachusetts Institute of science and technology through Internet. So it can be completely applied the concept of Maker education into the teaching of professional teaching, and recorded related interdisciplinary innovation courses guidance by a dedicated teacher in the school. With the help of MOOCs platform, to promote innovation and entrepreneurship education is in line with the requirements of today's era. Construct different levels of knowledge and ecological education system and format the hybrid multi-learning platform.

\section{G. Constructing the quality system of MOOCs learning platform in independent colleges}

Although the trend of MOOCs platform affects the reform of higher education, many independent colleges are hastily launched MOOCS education platform, and cooperation with educational institutions outside. But we should see the problems and return to the rational cognition level, we should adapt to the changes that it will brought about, the same problems we should face, the process of transformation is also a process of continuous improvement. There are also appeared brush class, high registration rate, low completion rate and other phenomena. At first, students are very positive, because the student lack of self-control and other factors, leading students more and more perfunctory, and finally just to complete the task. Then the meaning of learning, personalized learning, and the cultivation of students' innovative spirit is out of the question. Construction of planning quality monitoring system while students acquiring knowledge is the advantageous auxiliary form for the Maker teacher's guidance and discussion. In the form of discussion class, design class and so on, to improve and supplement the MOOCs learning platform, to better enhance the quality of teaching. The structure of teaching platform is shown in figure 1 .

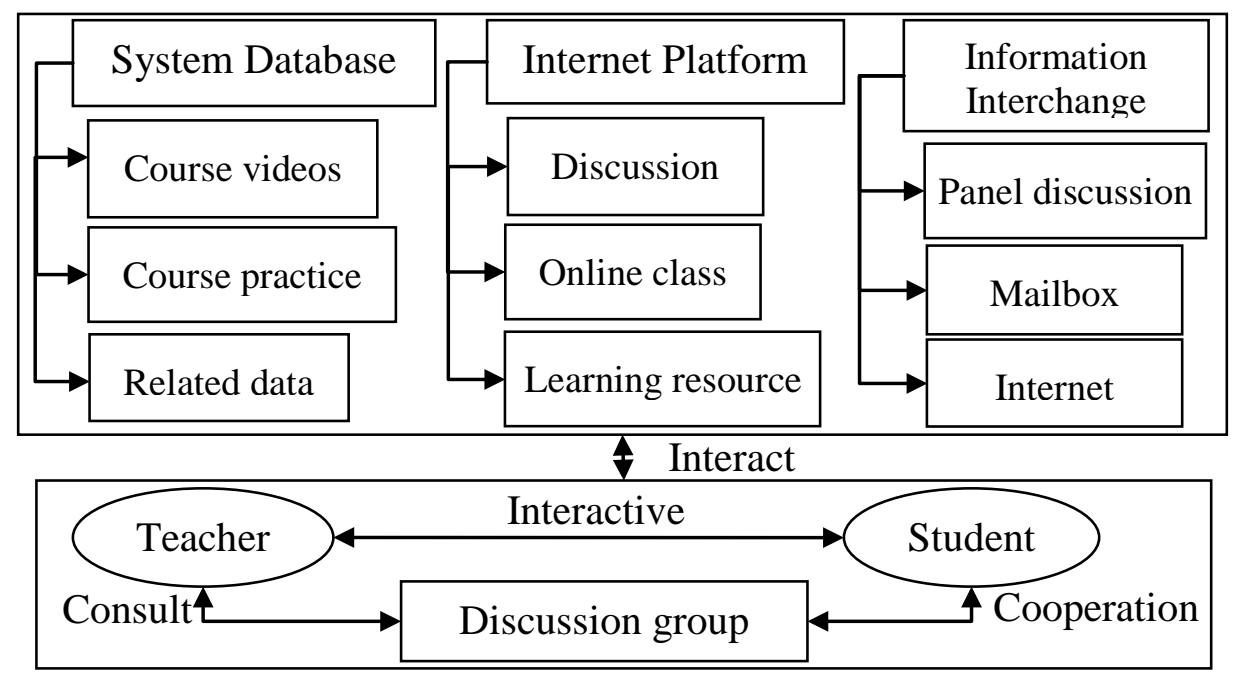

Fig. 1. The structure of teaching platform 


\section{CONCLUSION}

It is also need to carry out a lot of research on the MOOCs resources construction, teaching methods, teaching quality, evaluation methods and profit model, etc.[3]. MOOCs is not only involved in the teach students in accordance with their aptitude, but also considered curriculum design, teaching mode, resource optimization, technology realization and learning experience. Moreover, maintain good communication and cooperation with team members and technical support staff in the process of teaching, exert team practice innovation ability, complementary advantages, to provide better service for the course[4]. MOOCs can be the effective supplement in college classroom teaching, students can learn some simple points of knowledge through the vivid image of the MOOCs. Students can explore the depth of knowledge with teachers in the real class, stimulate innovation ability, and try to apply new knowledge to solve practical problems. The combination of MOOCs and traditional higher education may be the direction of the development and reform of college education in the future[5]. Also it is the reform direction of independent college to improve teaching quality and lifting its step.

\section{ACKNOWLEDGEMENTS}

This research was financially supported by the Research project of higher education teaching reform of Guangdong Province in 2014: Research on the multi-mixed education system of MOOCs learning platform in independent colleges

\section{REFERENCES}

[1] CHEN Mang, ZHANG Qing-pu, HUANG Chao, etc., Research on the Educational Innovation in MOOCs Based on Knowledge Ecology, eEducation Research, vol. 5, pp. 37-43, 2016.

[2] Zheng Qinhua, Yu Chang and Chen Li, A Survey of MOOCs Instructional Interaction in China on MOOC Students' Perspective, China Educational Technology, vol. 6, pp. 77-85, 2016.

[3] SUN Hongtao, ZHENG Qinhua and CHEN Li, A Survey of MOOC Instructional Interaction in China, Open Education Research, vol. 22, pp. 72-79, 2016.

[4] HUANG Guang-fang, WU Hong-yan and JIN Yi-fu, The Practice and Research on SPOC Effective Teaching in the U-Learning Environment, e-Education Research, vol. 5, pp. 50-57, 2016.

[5] WANG Hai-bo, Questioning the Statement of MOOCs Subverting Traditional Higher Education, Heilongjiang Researches on Higher Education, vol. 3, pp. 140-143, 2016. 